in vivo $35: 299-306(2021)$

doi:10.21873/invivo.12259

\title{
High MCM6 Expression as a Potential Prognostic Marker in Clear-cell Renal Cell Carcinoma
}

\author{
NU-RI JANG ${ }^{1}$, JINA BAEK ${ }^{1}$, YOUNGHWII KO ${ }^{2}$, PHIL HYUN SONG ${ }^{2}$ and MI-JIN GU ${ }^{1}$ \\ ${ }^{1}$ Department of Pathology, Yeungnam University College of Medicine, Gyeongsan, Republic of Korea; \\ ${ }^{2}$ Department of Urology, Yeungnam University College of Medicine, Gyeongsan, Republic of Korea
}

\begin{abstract}
Aim: Minichromosome maintenance (MCM) proteins are involved in initiation of DNA replication and cell-cycle progression. Loss of MCM function results in genomic instability and causes carcinogenesis. Among MCM genes, the role and prognostic value of MCM6 expression in clear-cell renal cell carcinoma (ccRCC) has not been elucidated. Materials and Methods: We assessed the mRNA expression level of MCM6 using the Gene Expression Profiling Interactive Analysis database and investigated MCM6 protein expression by immunohistochemistry in 238 ccRCC cases. Results: High MCM6 expression was significantly associated with increasing tumor size, $p T$, stage, tumor necrosis, and metastasis. Furthermore, high MCM6 expression was significantly associated with shorter overall and disease-free survival, and was an independent unfavorable prognostic marker. Regarding patients with metastasis, high MCM6-expressing ccRCC conferred significantly shorter survival than for those with low expression. Conclusion: A high MCM6 expression level may be a promising biomarker to predict tumor progression, metastasis, and survival in patients with ccRCC.
\end{abstract}

Clear-cell renal cell carcinoma (ccRCC) is the most common type of RCC, accounting for 70-80\% of all RCC cases $(1,2)$. Patients with ccRCC generally have worse outcomes compared to those with other RCC types (3). At diagnosis, one-third of patients with ccRCC already exhibit metastasis (4). Surgical resection is the most effective treatment for

This article is freely accessible online.

Correspondence to: Mi-Jin Gu, Ph.D., Department of Pathology, Yeungnam University College of Medicine, 170 Hyeonchung-ro, Nam-gu, Daegu 42415, Republic of Korea. Tel: +82 536406756, Fax: +82 526228432, e-mail: mjgu@yu.ac.kr

Key Words: MCM6, clear cell renal cell carcinoma, prognosis, biomarker. localized ccRCC, and its overall 5-year survival rate is up to $97.4 \%$ for stage I ccRCC and $89.9 \%$ for stage II (5). However, $30-35 \%$ of patients who undergo nephrectomy experience relapse and metastasis. Metastatic and inoperable ccRCC is refractory to conventional chemotherapy and radiotherapy and has a 5-year survival rate of approximately $20 \%(6,7)$. Therefore, the identification of potential biomarkers to predict disease progression and prognosis remains crucial.

The minichromosome maintenance (MCM) protein complex consists of six highly-conserved proteins (MCM27) and plays an essential role in the initiation of DNA replication (8). MCM proteins are expressed only during the cell cycle and are down-regulated and dissociated from chromatin in quiescent cells. Thus, they are considered useful proliferation markers $(9,10)$. In addition, the elevation or depletion of MCM levels causes genomic instability and leads to carcinogenesis (11). MCM6 expression has been evaluated in various human cancer types, including breast cancer, hepatocellular carcinoma, endometrial adenocarcinoma, craniopharyngioma, meningioma, chondrosarcoma, pancreatic adenocarcinoma, and colorectal cancer $(8,12-15)$. In those studies, MCM6 was found to be overexpressed in cancer tissue and was associated with important clinicopathologicaI factors. However, to the best of our knowledge, this is the first study to evaluate MCM6 protein expression and its prognostic significance in ccRCC.

The aim of this study was to assess the MCM6 expression level in ccRCC, evaluate its clinicopathological significance, and determine whether MCM6 can be used as a potential prognostic and predictive marker of ccRCC.

\section{Materials and Methods}

Public database analysis. We assessed the Gene Expression Profiling Interactive Analysis (GEPIA; http;//gepia.cancer-pku.cn) database to evaluate the RNA-Seq mRNA expression of MCM6 in 523 ccRCC samples and 100 normal samples from the Cancer Genome Atlas and Genotype-Tissue Expression (GTEx) projects. 


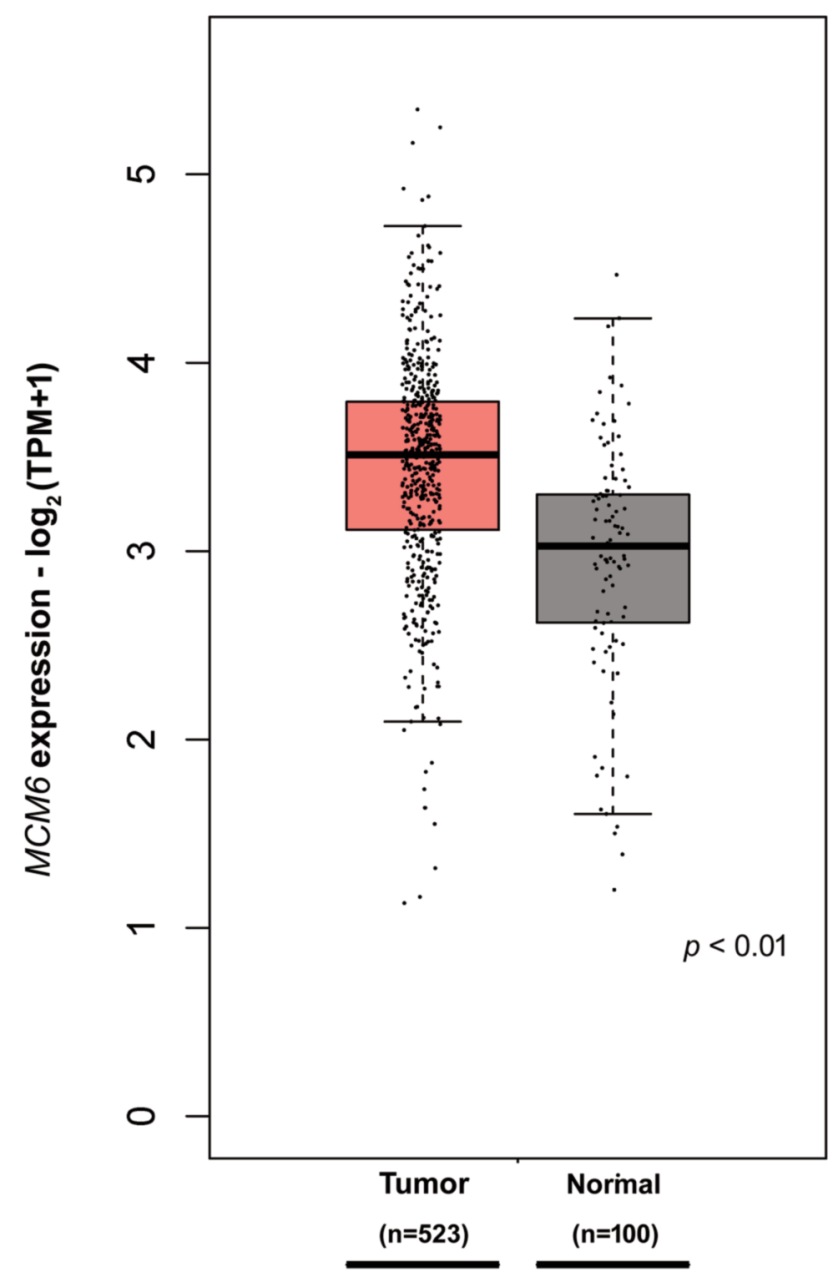

Figure 1. Distribution of minichromosome maintenance 6 (MCM6) gene expression in clear-cell renal carcinoma tissue and normal tissue. MCM6 gene was significantly up-regulated $(p<0.01)$ in clear-cell renal cell carcinoma [mean value of $\left.\log _{2}(T P M+1)\right]$. TPM: Transcripts per million.

Patient data and histological review. We included 238 cases of ccRCC who underwent nephrectomy between May 2000 and July 2017 at Yeungnam University Medical Center. This study was approved by the Ethics Committee of the Yeungnam University College of Medicine (2020-06-009). Written informed consent was exempted by the Ethics Committee due to the retrospective nature of the study. Clinical, pathological, and follow-up data were obtained from the patients' medical records. Cases that involved pre-operative therapy, insufficient clinicopathological data, or tissue unavailability for immunohistochemical staining were excluded from the analysis. The clinicopathological data included data regarding patient sex, age, tumor size, tumor necrosis, tumor hemorrhage, lymphovascular invasion (LVI), TNM (tumor, node, metastasis) stage, metastasis/recurrence, and nuclear grade (based on the 2016 World Health Organization classification of Tumors of the Urinary System and Male Genital Organs (2). Tumor grading and staging were performed according to the eighth American Joint

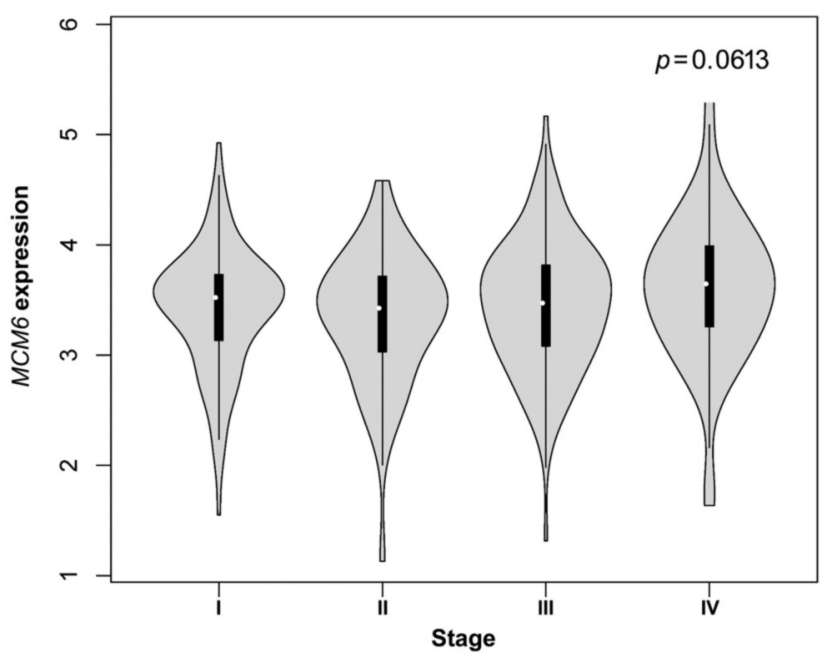

Figure 2. Distribution of minichromosome maintenance 6 (MCM6) gene expression in different stages of clear-cell renal cell carcinoma.

Committee on Cancer TNM Staging System (16). Overall survival (OS) was defined as the period from the date of diagnosis to the date of death. Disease-free survival (DFS) was evaluated as the period from the date of diagnosis to the date of first recurrence, distant metastasis, or last follow-up date. The OS and DFS data were obtained from the medical charts or the microdata integrated service of South Korea.

Tissue microarray construction. Tissue microarrays (TMAs) were constructed using paraffin-embedded blocks of ccRCC tissues. Two to four $1.5-\mathrm{mm}$ tissue cores that represented the tumor areas of patients were included in the TMA. Non-neoplastic kidney, lymph node, gastric mucosa, breast cancer, and normal liver parenchyma tissues were included as a control in each TMA section. One section from each TMA was stained with hematoxylin and eosin and assessed to confirm the histological presence of representative ccRCC features.

Immunohistochemical analyses and scoring. The 4- $\mu$ m-thick tissue sections were deparaffinized and rehydrated. Immunohistochemistry for MCM6 was performed using an automated Benchmark platform (Ventana Medical Systems, Tucson, AZ, USA). Antigen retrieval was carried out using the Cell Conditioning Solution (mild cc1; Ventana Medical Systems), and the samples were then incubated with MCM6 antibody (ERP17686, rabbit monoclonal, 1:1,000; Abcam, Cambridge, UK) for $40 \mathrm{~min}$ at room temperature. Stains were visualized using an UltraView universal DAB detection kit (Ventana Medical System). Negative controls were performed in the absence of primary antibody. The slides were then scanned using a Leica Aperio ScanScope (Leica Biosystems, Vista, CA, USA) system at $40 \times$ magnification, and the images were captured using a Leica ImageScope.

MCM6 expression was defined as positive when the tumor cells had moderate or strong nuclear immunoreactivity. Manual counting of MCM6-expressing cells was performed on a computer monitor using the scanned images. We selected two to four hotspots (with a minimum of 500 tumor cells) for each case, and all tumor nuclei 

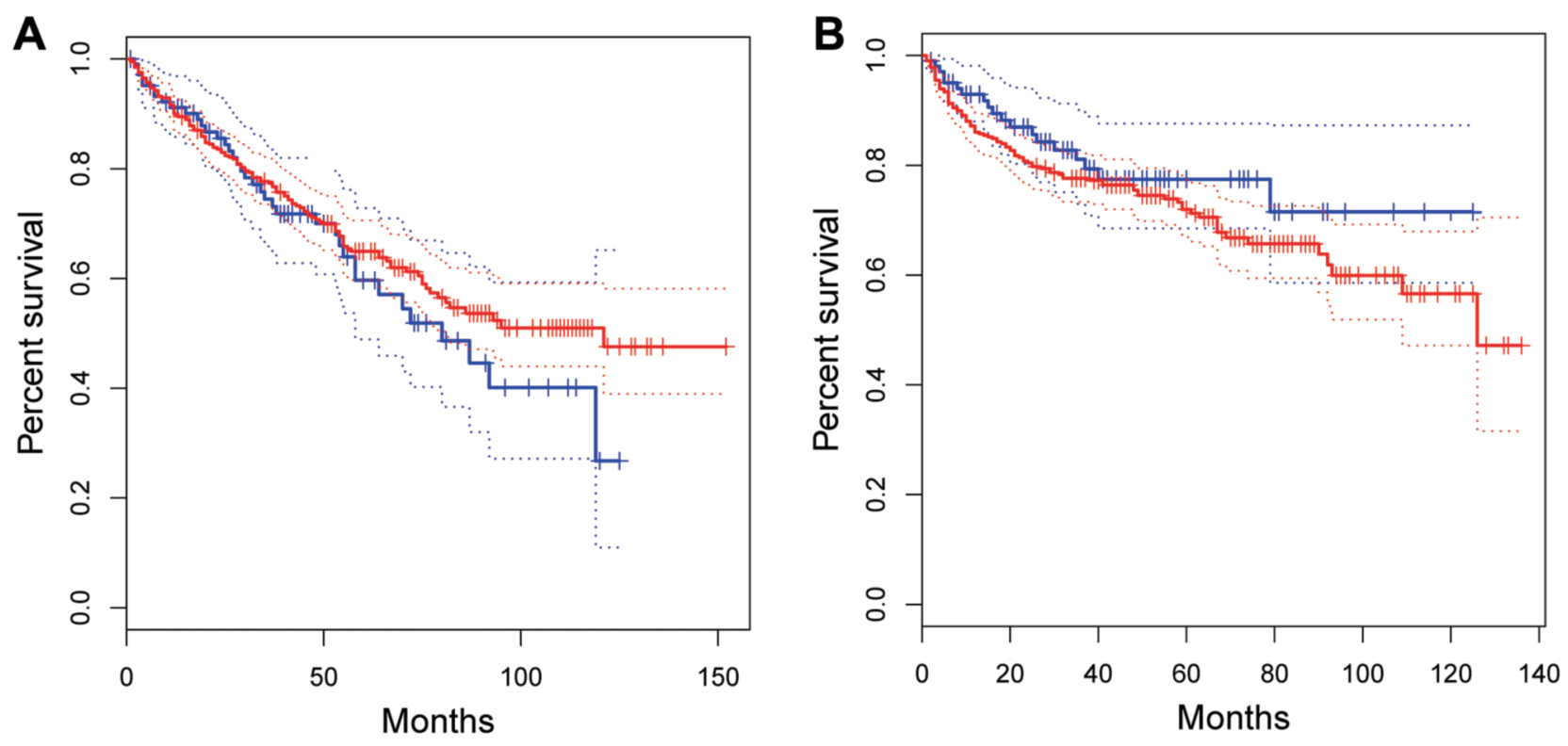

Figure 3. In the Gene Expression Profiling Interactive Analysis data, high minichromosome maintenance 6 (MCM6) gene expression tended to confer better overall $(A)(p=0.35)$ and worse disease-free $(B)(p=0.22)$ survival than low expression.
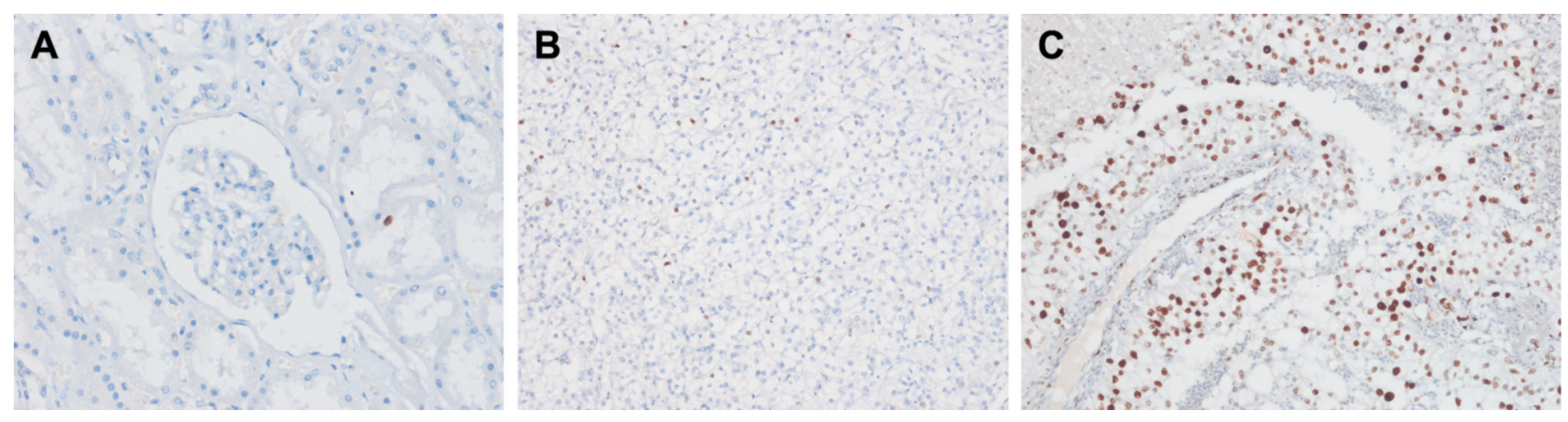

Figure 4. Immunohistochemical analysis of minichromosome maintenance 6 (MCM6) expression. A: MCM6 expression was found only rarely in tubule, not in glomeruli in normal kidney (×20). B: Low MCM6 expression (×10). C: High MCM6 expression $(\times 10)$.

and MCM6-positive tumor cells were counted by clicking on the images to yield a continuous score from 0 to 100 .

Statistical analysis. To identify the optimal cutoff value that would demonstrate the highest accuracy in predicting outcomes, receiver operating characteristic curve analysis was used. Quantitative variables were compared using Student's $t$-test. Categorical variables were compared using Fisher's exact test. OS and DFS curves were assessed using the Kaplan-Meier method and compared using the log-rank test. Multivariate Cox regression analyses were performed using pathological variables that were recognized as significant in the univariate survival analyses. Additionally, hazard ratios (HRs) and relevant 95\% confidence intervals (CIs) were assessed. All statistical analyses were conducted using SPSS software version 25.0 (IBM, Armonk, NY, USA). A $p$-value of less than 0.05 was considered statistically significant.

\section{Results}

mRNA expression of MCM6 gene. In the GEPIA data, the MCM6 gene was found to be up-regulated in the ccRCC samples when compared to normal kidney samples (Figure 1). The MCM6 gene expression level did not differ significantly between stages; however, it was found to be a slightly more up-regulated in stage IV ccRCC samples when compared to other stages (Figure 2). Patients with RCCs 
Table I. Relationships between minichromosome maintenance 6 (MCM6) expression and clinicopathological factors.

\begin{tabular}{|c|c|c|c|}
\hline \multirow[t]{2}{*}{ Variable } & \multicolumn{3}{|c|}{ MCM6 expression, n (\%) } \\
\hline & Low $(n=191)$ & $\operatorname{High}(n=47)$ & $p$-Value \\
\hline \multicolumn{4}{|l|}{ Gender } \\
\hline Male & $135(78.0)$ & $38(22.0)$ & \multirow[t]{2}{*}{0.161} \\
\hline Female & $56(86.2)$ & $9(13.8)$ & \\
\hline \multicolumn{4}{|l|}{ Tumor size } \\
\hline$\leq 4 \mathrm{~cm}$ & $112(84.8)$ & $20(15.2)$ & \multirow[t]{4}{*}{0.017} \\
\hline$<4-\leq 7 \mathrm{~cm}$ & $55(77.5)$ & $16(22.5)$ & \\
\hline$<7-\leq 10 \mathrm{~cm}$ & $16(72.7)$ & $6(27.3)$ & \\
\hline$>10 \mathrm{~cm}$ & $8(61.5)$ & $5(38.5)$ & \\
\hline \multicolumn{4}{|l|}{ Nuclear grade } \\
\hline 1 & $27(81.8)$ & $6(18.2)$ & \multirow[t]{4}{*}{0.001} \\
\hline 2 & $86(83.5)$ & $17(16.5)$ & \\
\hline 3 & $62(86.1)$ & $10(13.9)$ & \\
\hline 4 & $16(53.3)$ & $14(46.7)$ & \\
\hline \multicolumn{4}{|c|}{ Lymphovascular invasion } \\
\hline No & $180(81.8)$ & $40(18.2)$ & \multirow[t]{2}{*}{0.058} \\
\hline Yes & $11(61.1)$ & 7 (38.9) & \\
\hline \multicolumn{4}{|l|}{ Necrosis } \\
\hline No & $166(83.4)$ & $33(16.6)$ & \multirow[t]{2}{*}{0.006} \\
\hline Yes & $25(64.1)$ & $14(35.9)$ & \\
\hline \multicolumn{4}{|l|}{ Hemorrhage } \\
\hline No & $27(77.1)$ & $8(22.9)$ & \multirow[t]{2}{*}{0.617} \\
\hline Yes & $164(80.8)$ & $39(19.2)$ & \\
\hline \multicolumn{4}{|l|}{ T Status } \\
\hline pT1 & $161(83.9)$ & $31(16.1)$ & \multirow[t]{3}{*}{0.016} \\
\hline pT2 & $11(68.8)$ & $5(31.3)$ & \\
\hline pT3 & $19(63.3)$ & $11(36.7)$ & \\
\hline \multicolumn{4}{|l|}{ N Status } \\
\hline pNO & $17(70.8)$ & $7(29.2)$ & \multirow[t]{2}{*}{0.320} \\
\hline $\mathrm{pN} 1$ & $0(0)$ & $1(100)$ & \\
\hline \multicolumn{4}{|l|}{ Metastasis } \\
\hline No & $181(83.0)$ & $37(17.0)$ & \multirow[t]{2}{*}{0.001} \\
\hline Yes & $10(50.0)$ & $10(50.0)$ & \\
\hline \multicolumn{4}{|l|}{ Stage } \\
\hline I & $155(83.8)$ & $30(16,2)$ & \multirow[t]{4}{*}{0.001} \\
\hline II & $13(81.3)$ & $3(18.8)$ & \\
\hline III & $11(84.6)$ & $2(15.4)$ & \\
\hline IV & $12(50.0)$ & $12(50.0)$ & \\
\hline
\end{tabular}

with high MCM6 gene expression tended to have better OS and shorter DFS than those with lower expression $(p=0.35$ and $p=0.22$ ) (Figure 3 ).

Patient cohort and clinical characteristics. The patient cohort included in this study consisted of 238 patients (173 males and 65 females). The mean age was 57.6 years (range $=26-93$ years), and the tumor size ranged from 9 to $14.5 \mathrm{~cm}($ mean $=4.4 \mathrm{~cm})$. The mean follow-up time was 93.9 months (range $=1-217$ months). During the follow-up period, 20 patients $(8.4 \%)$ experienced tumor recurrence or metastasis and 26 patients $(10.9 \%)$ died.
Immunohistochemical analysis of MCM6 expression. MCM6 was found to be rarely expressed in non-neoplastic renal tubular epithelium $(<1 \%)$, and immunoreactivity was not observed in the glomerulus (Figure 4A). Notably, the MCM6 expression level in ccRCC samples (Figure 4B) ranged from $0 \%$ to $83 \%($ mean $=9.8 \%)$. The cutoff value for MCM6positivity with the highest accuracy was $20 \%$. The global predictive accuracy (area under the receiver operating characteristics curve) was found to be $0.709 \%(95 \%$ confidence intervaI $=0.588-0.830 ; p<0.0001)$. We therefore defined samples with high MCM6 expression as samples in which more than $20 \%$ of the tumor cells exhibited nuclear staining. Overall, 47 out of 238 (19.7\%) ccRCC samples showed high MCM6 expression (Figure 4C).

MCM6 expression is correlated with advanced clinicopathological factors. High MCM6 expression was significantly correlated with increasing tumor size $(p=0.025)$ and nuclear grade $(p=0.001)$, and with tumor necrosis $(p=0.006)$. MCM6 was found to be significantly overexpressed in patients with pT2 and pT3 when compared to those with pT1 $(p=0.016)$. In addition, a high MCM6 expression level was associated with metastasis $(p=0.001)$ and increasing stage $(p=0.004)$. Patients with LVI also tended to have higher MCM6 expression but the differences were not statistically significant $(p=0.058)$. No significant association was observed between high MCM6 expression and sex, tumor hemorrhage, or lymph node metastasis. The results are detailed in Table I.

MCM6 expression is associated with poor outcome. The Kaplan-Meier curve showed that patients with high MCM6 expression had a significantly worse OS and DFS (both $p<0.0001)$ compared to those with low MCM6 expression (Figures 5 and 6). In univariate analyses, OS and DFS were found to be shorter in patients with ccRCC with LVI, tumor necrosis, metastasis, and high MCM6 expression (all $p<0.0001$ ). Moreover, survival was found to worsen as pT stage increased. Patients with stage III or IV ccRCC were revealed to have a similar survival time of only a few months, which was significantly shorter compared to that of patients with stage I or II ccRCC. In multivariate analyses, high MCM6 expression and stage III and IV ccRCC were independent predictors of poorer OS and DFS. Additionally, the presence of metastases was found to be an independent prognostic factor for poorer DFS. The data are summarized in Table II and III.

\section{Discussion}

DNA replication is a key process in cell proliferation and growth (17). MCM proteins are key regulators of DNA replication, and dysregulation of MCM proteins may cause developmental defects or cancer (13). The up-regulation of MCM genes has been observed in many human cancer types 
Jang et al: MCM6 as a New Prognostic Biomarker in ccRCC

Table II. Univariate and multivariate analyses of the associations between clinicopathological factors and overall survival.

\begin{tabular}{|c|c|c|c|c|c|}
\hline \multirow[t]{2}{*}{ Variable } & \multirow[b]{2}{*}{ Comparison } & \multicolumn{2}{|c|}{ Univariate analysis } & \multicolumn{2}{|c|}{ Multivariate analysis } \\
\hline & & HR $(95 \%$ CI $)$ & $p$-Value & HR $(95 \%$ CI $)$ & $p$-Value \\
\hline LVI & Yes vs. no & $17.248(8.016-37.114)$ & $<0.0001$ & $1.569(0.558-4.412)$ & 0.393 \\
\hline Necrosis & Yes vs. no & $5.101(2.426-10.727)$ & $<0.0001$ & $1.798(0.642-5.036)$ & 0.264 \\
\hline \multirow[t]{2}{*}{ T Status } & pT1 vs. pT2 & $10.076(2.371-42.822)$ & 0.002 & $2.101(0.341-12.957)$ & 0.424 \\
\hline & pT1 vs. pT3 & $50.509(18.755-136.025)$ & $<0.0001$ & $1.986(0.504-7.820)$ & 0.327 \\
\hline Metastasis & Yes vs. no & $26.741(12.337-57.959)$ & $<0.0001$ & $5.326(0.704-40.292)$ & 0.105 \\
\hline \multirow[t]{3}{*}{ Stage } & I vs. II & $6.752(0.611-74.654)$ & 0.119 & $6.914(0.621-77.045)$ & 0.116 \\
\hline & I vs. III & $129.726(26.649-631.509)$ & $<0.0001$ & $208.776(9.686-626.395)$ & $<0.0001$ \\
\hline & I vs. IV & $108.983(25.153-472.203)$ & $<0.0001$ & $19.537(0.410-109.443)$ & 0.016 \\
\hline MCM6 expression & High vs. low & $4.893(2.327-10.288)$ & $<0.0001$ & $5.326(0.704-40.292)$ & 0.105 \\
\hline
\end{tabular}

CI: Confidence interval; HR: hazard ratio; LVI: lymphovascular invasion; MCM6: minichromosome maintenance 6. Statistically significant $p$-values are shown in bold.

Table III. Univariate and multivariate analyses of the associations between clinicopathological factors and overall survival.

\begin{tabular}{|c|c|c|c|c|c|}
\hline \multirow[t]{2}{*}{ Variable } & \multirow[b]{2}{*}{ Comparison } & \multicolumn{2}{|c|}{ Univariate analysis } & \multicolumn{2}{|c|}{ Multivariate analysis } \\
\hline & & $\mathrm{HR}(95 \% \mathrm{CI})$ & $p$-Value & $\mathrm{HR}(95 \% \mathrm{CI})$ & $p$-Value \\
\hline LVI & Yes vs. no & $17.529(8.140-37.750)$ & $<0.0001$ & $6.592(0.837-5.767)$ & 0.110 \\
\hline Necrosis & Yes vs. no & $5.363(2,549-11.284)$ & $<0.0001$ & $1.426(0.569-3.571)$ & 0.449 \\
\hline \multirow[t]{2}{*}{ T Status } & pT1 vs. pT2 & $9.379(2,212-39.763)$ & 0.002 & $3.610(0.504-25.855)$ & 0.201 \\
\hline & pT1 vs. pT3 & $55.121(20.137-150.883)$ & $<0.0001$ & $1.832(0.421-7.961)$ & 0.420 \\
\hline Metastasis & Yes vs. no & $38.159(17.263-84.350)$ & $<0.0001$ & $12.923(1.569-106.410)$ & 0.017 \\
\hline \multirow[t]{3}{*}{ Stage } & I vs. II & $6.399(0.579-70.712)$ & 0.130 & $6.218(0.557-69.424)$ & 0.138 \\
\hline & I $v s$. III & $107.492(22.000-525.201)$ & $<0.0001$ & $163.052(27.081-981.712)$ & $<0.0001$ \\
\hline & I vs. IV & $142.793(32.732-622.930)$ & $<0.0001$ & $15.034(1.343-168.317)$ & 0.028 \\
\hline MCM6 expression & High vs. low & $5.017(2.387-10.542)$ & $<0.0001$ & $4.458(1.755-11.324)$ & 0.002 \\
\hline
\end{tabular}

CI: Confidence interval; HR: hazard ratio; LVI: lymphovascular invasion; MCM6: minichromosome maintenance 6. Statistically significant $p$-values are shown in bold.

and was associated with histological grade, TNM stage, or survival (9). However, some controversial results have been reported in colorectal cancer and lung adenocarcinoma (18). Gou et al. reported in a meta-analysis that MCM2, MCM5, and MCM7 were associated with worse outcomes in human cancer (18). In addition, several studies have also assessed the clinicopathological significance of MCM protein expression, and its role as a proliferation marker in comparison to Ki-67. Notably, the majority of those studies were mainly conducted on MCM2 protein expression among the MCM family members. The results of those studies showed that high MCM2 expression was a marker of poor prognosis and MCM2 was proven to be a more reliable and useful proliferation marker than Ki-67 in many types of human cancer $(8,9,19-21)$. The prognostic value of Ki-67 in RCC is controversial and inconsistent. Some studies have reported that a high Ki-67 index is correlated with an unfavorable prognosis in RCC (22-24). In contrast, other studies found that the Ki-
67 index was not associated with prognosis $(25,26)$. The aforementioned studies used different cutoff values for positive Ki-67 expression, ranging between 5 and $50 \%$. Additionally, tumor proliferation markers, including Ki-67, are not routinely used to predict prognosis in RCC.

High MCM6 expression was associated with poor survival and higher histological grade in endometrioid endometrial adenocarcinoma and low-grade chondrosarcoma $(15,27)$. Patients with high MCM6 expression level in non-small cell lung cancer, mantle cell lymphoma, and craniopharyngioma were also found to have worse survival and an increased risk of death $(15,28,29)$. In breast cancer, high MCM6 expression was also associated with a higher histological grade (14). Notably, in hepatocellular carcinoma, MCM6 was found to be the best diagnostic and prognostic marker when compared to the other MCM proteins (30).

There have been a few studies that have investigated the expression of MCM proteins in RCC but the majority of 

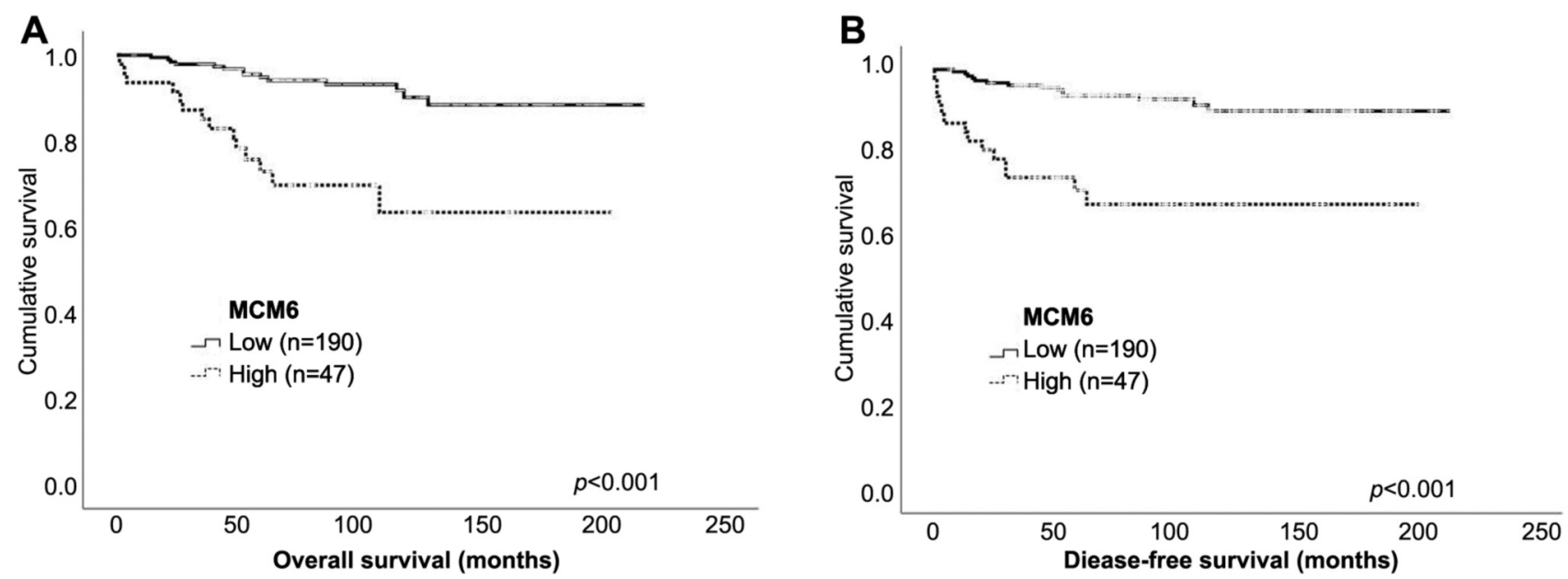

Figure 5. Survival curves for the whole patient cohort according to minichromosome maintenance 6 (MCM6) protein expression. A: Cumulative overall survival. B: Disease-free survival. High MCM6 expression was significantly associated with worse survival.

A

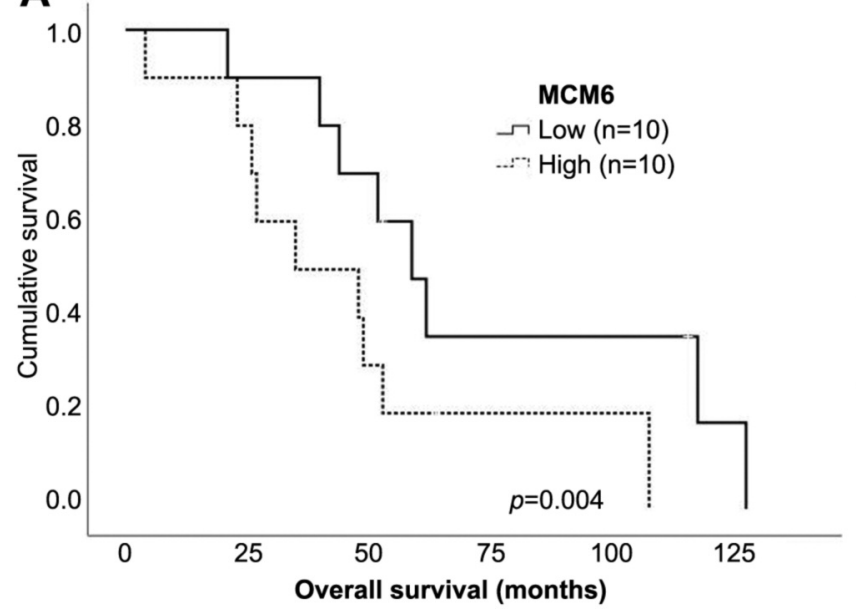

B

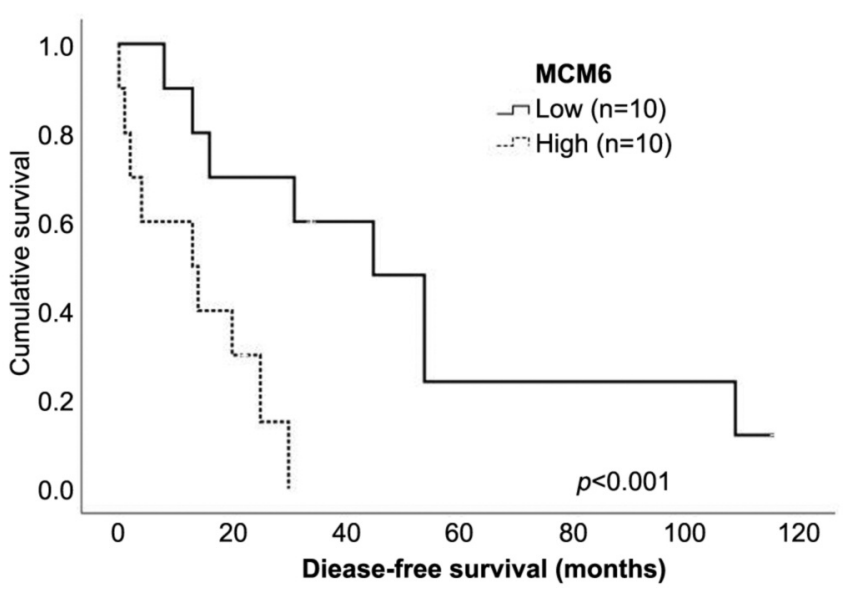

Figure 6. Survival curves according to minichromosome maintenance 6 (MCM6) protein expression in patients with metastasis of clear-cell renal cell carcinoma. Those with high MCM6 expression had significantly worse overall (A) and disease-free (B) survival.

those studies were on the MCM2 expression in RCC. In addition, they included all histological types of RCC ccRCC, papillary RCC, chromophobe RCC, transitional cell carcinoma, and even oncocytoma (21, 31-33). These studies suggested that MCM2 is a useful proliferation marker, and its expression is associated with nuclear grade $(21,31,33)$. In a study using gene-expression data, the overexpression of MCM genes was found to be an independent prognostic factor of RCC (34). That study was also conducted on all histological types of RCC. High MCM5 expression in RCC was associated with lymph node metastasis, distant metastasis, clinical stage, and a shorter OS (32).
In the present study, high MCM6 expression in ccRCC was found to be correlated with aggressive clinicopathological factors and especially associated with tumor progression (as reflected by increasing tumor size, pT stage, stage, and metastasis). Similar to the GEPIA results, the frequency of high MCM6 expression was not significantly different between stage I, II, and III ccRCC, but was a little up-regulated in stage IV ccRCC. This suggests that high MCM6 expression may be associated with metastasis rather than disease stage, as there was no pT4 case included in the present study. Furthermore, in ccRCC with metastasis, patients with high MCM6 expression had a significantly shorter OS (mean=48.1 months) and DFS (mean=13.7 months) than those with low MCM6 expression 
(mean of 74.5 months and 52.2 months) (Figure 6). This might support our hypothesis that MCM6 plays an oncogenic role in tumor proliferation and progression, and suggests that it might be a promising potential prognostic marker for ccRCC. The MCM6 labeling index with a cutoff value of $20 \%$ was found to be a highly significant predictor of aggressive clinicopathological factors, metastasis, and poor survival. However, further studies with a larger number of ccRCC cases are required to validate the cutoff value.

In conclusion, our study is the first to assess MCM6 expression and its prognostic value in ccRCC. As such, we revealed that high MCM6 expression was significantly associated with aggressive clinicopathological factors and was an independent adverse prognostic factor. Thus, the assessment of MCM6 expression in patients with ccRCC as a routine pathological practice might provide useful information in regard to aggressive behavior. Additionally, MCM6 expression might be a useful predictive marker of metastasis and poor survival. However, future studies are needed to verify the cutoff value of MCM6 expression and to investigate whether MCM6 can serve as a potential therapeutic target.

\section{Conflicts of Interest}

The Authors declare that they have no conflicts of interest.

\section{Authors' Contributions}

MJG carried out experiments, analyzed data, and prepared the article. NRJ and JAB reviewed pathological data, carried out experiments and analyzed data. YWK and PHS prepared clinical data.

\section{Acknowledgements}

This work was supported by a grant from the Chunma Medical Research Foundation, Korea, 2020.

\section{References}

1 Rini BI, Campbell SC and Escudier B: Renal cell carcinoma. Lancet 373(9669): 1119-1132, 2009. PMID: 26935559. DOI: 10.1016/j.eururo.2016.02.029

2 Moch H, Cubilla AL, Humphrey PA, Reuter VE and Ulbright TM: The 2016 WHO Classification of Tumours of the Urinary System and Male Genital Organs-Part A: Renal, Penile, and Testicular Tumours. Eur Urol 70(1): 93-105, 2016. PMID: 26935559. DOI: 10.1016/j.eururo.2016.02.029

3 Lopez-Beltran A, Carrasco JC, Cheng L, Scarpelli M, Kirkali Z and Montironi R: 2009 Update on the classification of renal epithelial tumors in adults. Int J Urol 16(5): 432-443, 2009. PMID: 19453547. DOI: 10.1111/j.1442-2042.2009.02302.x

4 Dagher J, Kammerer-Jacquet SF, Dugay F, Beaumont M, Lespagnol A, Cornevin L, Verhoest G, Bensalah K, RiouxLeclercq $\mathrm{N}$ and Belaud-Rotureau MA: Clear-cell renal cell carcinoma: A comparative study of histological and chromosomal characteristics between primary tumors and their corresponding metastases. Virchows Arch 471(1): 107-115, 2017. PMID: 28488172. DOI: $10.1007 / \mathrm{s} 00428-017-2124-0$

5 Cheaib JG, Patel HD, Johnson MH, Gorin MA, Haut ER, Canner JK, Allaf ME and Pierorazio PM: Stage-specific conditional survival in renal cell carcinoma after nephrectomy. Urol Oncol 38(1): 6 e1-6 e7, 2020. PMID: 31522864. DOI: 10.1016/j.urolonc.2019.08.011

6 Shinmei S, Goto K, Sentani K, Anami K, Hayashi T, Teishima J, Matsubara A, Oue N, Kitadai Y, Yasui W and Yasui W: MicroRNA-155 is a predictive marker for survival in patients with clearcell renal cell carcinoma. Int J Urol 20(5): 468-477, 2013. PMID: 23050614. DOI: 10.1111/j.1442-2042.2012.03182.x

7 Ficarra V, Guillè F, Schips L, de la Taille A, Prayer Galetti T, Tostain J, Cindolo L, Novara G, Zigeuner R, Bratti E, Li G, Altieri V, Abbou CC, Zanolla L, Artibani W, and Patard J-J: Proposal for revision of the TNM classification system for renal cell carcinoma. Cancer 104(10): 2116-2123, 2005. PMID: 16208703. DOI: $10.1002 / \mathrm{cncr} .21465$

8 Gauchotte G, Vigouroux C, Rech F, Battaglia-Hsu SF, Soudant M, PineIli C, Civit T, Taillandier L, Vignaud JM and Bressenot A: Expression of mini-chromosome maintenance MCM6 protein in meningiomas is strongly correlated with histological grade and clinical outcome. Am J Surg Pathol 36(2): 283-291, 2012. PMID: 22020044. DOI: 10.1097/PAS.0b013e318235ee03

9 Giaginis C, Vgenopoulou S, Vielh P and Theocharis S: Mcm proteins as diagnostic and prognostic tumor markers in the clinical setting. Histol Histopathol 25(3): 351-370, 2010. PMID: 20054807. DOI: $10.14670 / \mathrm{HH}-25.351$

10 Bailis JM and Forsburg SL: MCM proteins: DNA damage, mutagenesis and repair. Curr Opin Genet Dev 14(1): 17-21, 2004. PMID: 15108800 . DOI: $10.1016 /$ j.gde.2003.11.002

11 Das M, Singh S, Pradhan S and Narayan G: MCM PARadox: Abundance of eukaryotic replicative helicases and genomic integrity. Mol Biol Int 2014: 574850, 2014. PMID: 25386362. DOI: $10.1155 / 2014 / 574850$

12 Hendricks AA-O, Gieseler F, Nazzal S, Bräsen JH, Lucius R, Sipos B, Claasen JH, Becker T, Hinz S, Burmeister G, Schafmayer C and Schrader C: Prognostic relevance of topoisomerase II $\alpha$ and minichromosome maintenance protein 6 expression in colorectal cancer. BMC Cancer 19(1): 429, 2019. PMID: 31072339. DOI: 10.1186/s12885-019-5631-3

13 Liao X, Han C, Wang X, Huang K, Yu T, Yang C, Huang R, Liu Z, Han Q and Peng T: Prognostic value of minichromosome maintenance mrna expression in early- stage pancreatic ductal adenocarcinoma patients after pancreaticoduodenectomy. Cancer Manage Res 10: 3255-3271, 2018. DOI: 10.2147/CMAR. S171293

14 Issac MSM, Yousef E, Tahir MR and Gaboury LA: MCM2, MCM4, and MCM6 in breast cancer: Clinical utility in diagnosis and prognosis. Neoplasia 21(10): 1015-1035, 2019. PMID: 31476594. DOI: 10.1016/j.neo.2019.07.011

15 Hotton J, Agopiantz M, Leroux A, Charra-Brunaud C, Marie B, Busby-Venner H, Morel O, Gueant JL, Vignaud JM, BattagliaHsu SF and Gauchotte G: Minichromosome maintenance complex component 6 (MCM6) expression correlates with histological grade and survival in endometrioid endometrial adenocarcinoma. Virchows Arch 472(4): 623-633, 2018. PMID: 29243125. DOI: 10.1007/s00428-017-2278-9 
16 Amin MB and Edge SB: AJCC Cancer Staging Manual. Springer, 2017.

17 Kaur G, Balasubramaniam SD, Lee YJ, Balakrishnan V and Oon CE: Minichromosome maintenance complex (MCM) genes profiling and MCM2 protein expression in cervical cancer development. Asian Pac J Cancer Prev 20(10): 3043-3049, 2019. PMID: 31653153. DOI: 10.31557/APJCP.2019.20.10.3043

18 Gou K, Liu J, Feng X, Li H, Yuan Y and Xing C: Expression of minichromosome maintenance proteins $(\mathrm{MCM})$ and cancer prognosis: A meta-analysis. J Cancer 9(8): 1518-1526, 2018. PMID: 29721062. DOI: 10.7150/jca.22691

19 Shetty A, Loddo M, Fanshawe T, Prevost AT, Sainsbury R, Williams GH and Stoeber K: DNA replication licensing and cell cycle kinetics of normal and neoplastic breast. Br J Cancer 93(11): 1295-1300, 2005. PMID: 16278669. DOI: 10.1038/ sj.bjc. 6602829

20 Huang HY, Huang WW, Lin CN, Eng HL, Li SH, Li CF, Lu D, Yu SC and Hsiung CY: Immunohistochemical expression of p16 INK4A, KI-67, and MCM2 proteins in gastrointestinal stromal tumors: Prognostic implications and correlations with risk stratification of nih consensus criteria. Ann Surg Oncol 13(12): 1633-1644, 2006. PMID: 17013685. DOI: 10.1245/s10434-0069188-4

21 Rodins K, Cheale M, Coleman N and Fox SB: Minichromosome maintenance protein 2 expression in normal kidney and renal cell carcinomas: Relationship to tumor dormancy and potential clinical utility. Clin Cancer Res 8(4): 1075-1081, 2002. PMID: 11948116

22 Virman JP, Bono P, Luukkaala TH, Sunela KL, Kujala PM and Kellokumpu-Lehtinen PL: Combined angiogenesis and proliferation markers' expressions as long-term prognostic factors in renal cell cancer. Clin Genitourin Cancer 14(4): e283289, 2016. PMID: 26821530. DOI: 10.1016/j.clgc.2015.12.014

23 Weber T, Meinhardt M, Zastrow S, Wienke A, Fuessel S and Wirth MP: Immunohistochemical analysis of prognostic protein markers for primary localized clear cell renal cell carcinoma. Cancer Invest 31(1): 51-59, 2013. PMID: 23327192. DOI: 10.3109/07357907.2012.749267

24 Teng J, Gao Y, Chen M, Wang K, Cui X, Liu Y and Xu D: Prognostic value of clinical and pathological factors for surgically treated localized clear cell renal cell carcinoma. Chin Med J 127(9): 1640-1644, 2014. PMID: 24791867.

25 Zheng K, Zhu W, Tan J, Wu W, Yang S and Zhang J: Retrospective analysis of a large patient sample to determine p53 and Ki67 expressions in renal cell carcinoma. J BUON 19(2): 512-516, 2014. PMID: 24965414.

26 Gontero P, Ceratti G, Guglielmetti S, Andorno A, Terrone C, Bonvini D, Faggiano F, Tizzani A, Frea B and Valente G: Prognostic factors in a prospective series of papillary renal cell carcinoma. BJU Int 102(6): 697-702, 2008. PMID: 18489525. DOI: $10.1111 / \mathrm{j} .1464-410 X .2008 .07756 . \mathrm{x}$
27 Helfenstein A, Frahm SO, Krams M, Drescher W, Parwaresch R and Hassenpflug J: Minichromosome maintenance protein (MCM6) in low-grade chondrosarcoma: Distinction from enchondroma and identification of progressive tumors. Am J Clin Pathol 122(6): 912-918, 2004. PMID: 15539383. DOI: 10.1309/G638-TKNN-G2CJ-UXWL

28 Vigouroux C, Casse JM, Battaglia-Hsu SF, Brochin L, Luc A, Paris C, Lacomme S, Gueant JL, Vignaud JM and Gauchotte G: Methyl(r217)HUR and MCM6 are inversely correlated and are prognostic markers in non small cell lung carcinoma. Lung Cancer 89(2): 189-196, 2015. PMID: 26013954. DOI: 10.1016/ j.lungcan.2015.05.008

29 Xu J, Zhang S, You C, Huang S, Cai B and Wang X: Expression of human MCM6 and DNA TOPO II alpha in craniopharyngiomas and its correlation with recurrence of the tumor. J Neurooncol 83(2): 183-189, 2007. PMID: 17410335. DOI: $10.1007 / \mathrm{s} 11060-006-9284-0$

30 Liu M, Hu Q, Tu M, Wang X, Yang Z, Yang G and Luo R: MCM6 promotes metastasis of hepatocellular carcinoma via MEK/ERK pathway and serves as a novel serum biomarker for early recurrence. J Exp Clin Cancer Res 37(1): 10, 2018. PMID: 29357919. DOI: 10.1186/s13046-017-0669-z

31 Dudderidge TJ, Stoeber K, Loddo M, Atkinson G, Fanshawe T, Griffiths DF and Williams GH: MCM2, geminin, and Ki67 define proliferative state and are prognostic markers in renal cell carcinoma. Clin Cancer Res 11(7): 2510-2517, 2005. PMID: 15814627. DOI: 10.1158/1078-0432.CCR-04-1776

32 Gong B, Ma M, Yang X, Xie W, Luo Y and Sun T: MCM5 promotes tumour proliferation and correlates with the progression and prognosis of renal cell carcinoma. Int Urol Nephrol 51(9): 1517-1526, 2019. PMID: 31190295. DOI: 10.1007/s11255-019-02169-3

33 Mehdi MZ, Nagi AH and Naseem N: MCM-2 and Ki-67 as proliferation markers in renal cell carcinoma: A quantitative and semi - quantitative analysis. Int Braz J Urol 42(6): 1121-1128, 2016. PMID: 27532114. DOI: 10.1590/S1677-5538.IBJU. 2015.0388

34 Zhong H, Chen B, Neves H, Xing J, Ye Y, Lin Y, Zhuang G, Zhang SD, Huang $J$ and Kwok HF: Expression of minichromosome maintenance genes in renal cell carcinoma. Cancer Manag Res 9: 637-647, 2017. PMID: 29180899. DOI: 10.2147/CMAR.S146528

Received September 17, 2020

Revised October 3, 2020

Accepted October 7, 2020 